\title{
Trihalomethane Formation Potential in the Water Treated by Coagulation
}

\author{
Lidia Dąbrowska' \\ ${ }^{1}$ Faculty of Infrastructure and Environment, Czestochowa University of Technology, Dąbrowskiego 73, \\ 42-201 Częstochowa, Poland \\ e-mail: dabrowska@is.pcz.czest.pl
}

\begin{abstract}
The aim of the research was to evaluate the effectiveness of the coagulation process using pre-hydrolysed salts, polyaluminium chlorides, in reduction of water pollution with organic substances, including precursors to formation of trihalomethanes (THMs) during water chlorination. Surface water collected from the Stradomka river and from the Adriatyk reservoir located in Częstochowa was used for the research. In addition to typical indices used to assess the content of organic compounds (total and dissolved organic carbon TOC and DOC, oxygen consumption, ultraviolet absorbance $\mathrm{UV}_{254}$ ), the study also evaluated the potential of THM formation. Under the laboratory conditions of the process using pre-hydrolysed coagulants, reductions in oxygen consumption and TOC contents depending on the month and place when water was collected were $17-42 \%$ and $14-38 \%$, respectively, whereas reduction in $\mathrm{UV}_{254}$ absorbance ranged from 39 to $69 \%$. The study confirmed the usefulness of the coagulation process in the removal of organic matter, which represents a precursor for formation of trihalomethanes. The potential for THM formation in treated water was by $28-55 \%$ lower than in untreated surface water after chlorination. The concentration of trichloromethane was $78-93 \%$ of the total THM content in the chlorinated treated waters. Dissolved organic matter played a major role in $\mathrm{CHCl}_{3}$ formation (76-88\%).
\end{abstract}

Keywords: coagulation process, organic matter, trihalomethanes, water

\section{INTRODUCTION}

Organic matter can occur in water in dissolved form, defined as dissolved organic carbon (DOC), and in colloidal form and suspension, defined as suspended organic carbon. Approximately $80-90 \%$ of DOC in surface waters consists of humic substances formed as a result of microbiological reactions leading to the decomposition of dead plant and animal tissues. The structure of humic substances is not yet fully understood, however it is assumed that their molecules contain both aromatic structures, as well as aliphatic chains substituted with functional groups containing primarily oxygen, nitrogen and sulphur atoms [Nawrocki 2010].

Particular increase of interest in the composition of humic substances in water is noted since the publication of research regarding the generation of trihalomethanes (THMs) during the chlorination of water. THMs include: trichloromethane $\left(\mathrm{CHCl}_{3}\right)$, tribromomethane $\left(\mathrm{CHBr}_{3}\right)$, bromodichloromethane $\left(\mathrm{CHCl}_{2} \mathrm{Br}\right)$, and dibromochloromethane $\left(\mathrm{CHClBr}_{2}\right) \cdot \mathrm{CHCl}_{3}$ and $\mathrm{CHCl}_{2} \mathrm{Br}$ have been classified as potentially carcinogenic to humans [Guidelines 2011].

The permissible concentration of $\mathrm{CHCl}_{3}$, $\mathrm{CHCl}_{2} \mathrm{Br}$ and the sum of four THM content in water intended for human consumption stated in The Ministry of Health Regulation of year 2017 amount to 30,15 and $100 \mu \mathrm{g} / \mathrm{dm}^{3}$, respectively [Regulation 2017]. Presence of THMs in chlorinated water continues to represent a problem in water treatment plants [Font-Ribera et al. 2017, Golea et al. 2017, Niu et al. 2017]. Therefore, the removal of THM precursors is one of the most important tasks of a water treatment plant.

The prevention of the THM formation is the removal of organic matter from water, primarily humic and fulvic acids. Different 
technological processes may be used to reduce the content of organic compounds in water, i.a. coagulation, adsorption, ion exchange, biodegradation, advanced oxidation processes, and membrane processes [Bhatnagar and Sillanpää 2017, Zainudin et al. 2018]. However, coagulation and adsorption on activated carbon supported by ozonation are prevalent in the systems for treatment of water intended for human consumption. The effectiveness of coagulation depends on the physicochemical composition of water, the $\mathrm{pH}$ value, the type and dosage of coagulants [Zhang et al. 2018, Sillanpää et al. 2018, Kaleta and Puszkarewicz 2019].

More and more often in this process, prehydrolysed salts, e.g. polyaluminium chlorides with the general formula of $\mathrm{Al}_{\mathrm{n}}(\mathrm{OH})_{\mathrm{m}} \mathrm{Cl}_{3 \mathrm{n}-\mathrm{m}}$ are being used instead of aluminium sulphate(VI). With the controlled initial hydrolysis of aluminium salts occurring during production of polyaluminium chlorides, they contain more polymerized aluminium forms with a high positive charge compared to those generated during typical hydrolysis of aluminium sulphate. After addition of polyaluminium chloride to the treated water, polycationic products of aluminium pre-hydrolysis are much slower hydrolysed to $\mathrm{Al}(\mathrm{OH})_{3}$ compared to aluminium present in the aluminium sulphate solution. Consequently, the use of polyaluminium chlorides becomes more effective in destabilizing negative colloids that modify water colour and lead to turbidity compared to the effects achieved using aluminium sulphate. It is also important to evaluate the effectiveness of the coagulation process in removing organic compounds. Natural organic matter NOM is a complex mixture of heterogeneous organic compounds that vary in size, structure and functionality; more importantly the molecular weight of NOM is associated with THM formation [Marais et al. 2019].

The removal of NOM is not necessarily related to the removal of THM precursors. That is why the trihalomethane formation potential of the organic matter remaining in the analysed waters after their purification in the coagulation process was determined. On this basis, the effectiveness of coagulation as a process decreasing the THM formation potential was evaluated and the best coagulant was indicated. It was assessed to what extent dissolved and suspended (undissolved) organic matter was responsible for THM formation during chlorination of water.

\section{MATERIALS AND METHODS}

Surface water collected from the Stradomka river and from the reservoir Adriatyk located in Częstochowa in March and June 2019 was used for the research.

Pre-hydrolysed polyaluminium chlorides with the trade names PAX18, PAX-XL10 and PAXXL19F (manufactured by KEMIPOL in Police, Poland) were used as coagulants. These coagulants and their dose were adopted based on previous studies [Sperczyńska et al. 2016, Dąbrowska 2018]. Commercial solutions of the coagulants were characterized by basicity of $41,70,85 \%$ and $\mathrm{Al}_{2} \mathrm{O}_{3}$ content of $17.0,9.4$, and $16.1 \%$ for PAX18, PAX-XL10 and PAX-XL19F, respectively. The basicity of polyaluminium chlorides is defined by the ratio of $\mathrm{OH}^{-}$moles to $\mathrm{Al}^{3+}$ moles in coagulant. The ratio is defined as coefficient $r=\left[\mathrm{OH}^{-}\right] /$ $\left[\mathrm{Al}^{3+}\right]$. There is the following correlation between " $\mathrm{r}$ " and basicity of coagulant: basicity $(\%)=$ $\mathrm{r} / 0.03$. Working solutions of coagulants were prepared by diluting commercial products to contain $1.0 \mathrm{gAl} / \mathrm{dm}^{3}$ of solution.

The water after collection was transported to the laboratory and stored until the following day at a temperature of $4^{\circ} \mathrm{C}$. For the execution of the coagulation process, a coagulator with mechanical stirrer and glass beakers with a capacity of $2 \mathrm{dm}^{3}$ were used. $1.5 \mathrm{dm}^{3}$ of analyzed water was measured into the beakers. The coagulants were introduced at a dose of $3.0 \mathrm{mgAl} / \mathrm{dm}^{3}$. Stirring was carried out applying $250 \mathrm{rpm}$ for 2 minutes and then $25 \mathrm{rpm}$ for 15 minutes. After this time the samples were subjected to $1 \mathrm{~h}$ of sedimentation. Next, $0.3 \mathrm{dm}^{3}$ of water was decanted and the analyses were performed to determine $\mathrm{pH}$, turbidity, colour, oxygen consumption (oxidisability), total and dissolved organic carbon (TOC and DOC), ultraviolet absorbance, and potential of THM formation.

In the next stage of the study the coagulation process was repeated using chosen polyaluminum chloride.

The surface water quality indices before and after the coagulation process, were determined using the following methods: $\mathrm{pH}-$ potentiometric, turbidity - nephelometric (Eutech Instruments TN-100 turbidity meter), colour - comparison with standards on the platinum-cobalt scale, ultraviolet absorbance at $254 \mathrm{~nm}$ wavelength ( $1 \mathrm{~cm}$ cuvette) using the Camspec M501 spectrophotometer, oxygen 
consumption - permanganate method, TOC and DOC (after water filtration through 0.45 $\mu \mathrm{m}$ membrane filter) - by infrared spectrophotometry (Analytik Jena's Multi N/C analyzer). The colour was determined twice, whereas other indices were measured in triplicate. SUVA (ratio of $\mathrm{UV}_{254}$ absorbance to DOC value) was calculated to determine the properties of dissolved organic substances in water and their susceptibility to removal by coagulation.

To determine the potential of formation of THM-PF trihalomethanes, $50 \mathrm{~cm}^{3}$ of raw water or water after coagulation was poured into dark bottles. A dose of chlorine water prepared from sodium hypochlorite was such that after 24 hours at a temperature of ca. $22^{\circ} \mathrm{C}$, the concentration of free chlorine ranged from 3 to $5 \mathrm{mgCl}_{2} / \mathrm{dm}^{3}$ [Standard methods 1998]. To determine the concentration of THMs in water samples after 24 hours, $10 \mathrm{~cm}^{3}$ of water was collected to the test tubes and $1 \mathrm{~cm}^{3}$ of n-pentane was added, followed by intensive shaking for 3 minutes. After separation of the layers, a $2 \mu 1$ extract was sampled with a microsyringe, followed by the separation of the compounds on a DB-5 capillary column $(30 \mathrm{~m} \times 0.25 \mathrm{~mm} \times 0.25 \mathrm{~mm})$ and analysis by means of gas chromatography with an electron capture detector (Agilent $6890 \mathrm{~N}$, Agilent Technologies). The analyses were performed in triplicate.

The potential for THM formation in chlorinated raw water and treated water passed through a $0.45 \mu \mathrm{m}$ membrane filter, was also determined in a way described above.

\section{RESULTS AND DISCUSSION}

Mean values of water quality indices: $\mathrm{pH}$, turbidity, colour, total and dissolved organic carbon (TOC and DOC), oxygen consumption (OC), ultraviolet absorbance $\mathrm{UV}_{254}$ before and after the coagulation performed using PAX18, PAX-XL10 and PAX-XL19F at a dose of $3 \mathrm{mgAl} / \mathrm{dm}^{3}$ are presented in Tables 1 to 3 .

Surface water collected in March and June 2019 was characterized by turbidity ranging from 5.2 to $20.5 \mathrm{NTU}$ and the colour from 15 to $45 \mathrm{mgPt} / \mathrm{dm}^{3}$. The $\mathrm{pH}$ was slightly alkaline (7.06 to 7.94). The content of TOC ranged from 7.6 to $14.1 \mathrm{mgC} / \mathrm{dm}^{3}$, whereas OC ranged from 4.6 to $9.3 \mathrm{mgO}_{2} / \mathrm{dm}^{3}$. The $\mathrm{UV}_{254}$ absorbance was from 8.5 to $25.8 \mathrm{~m}^{-1}$.

The most effective in removal of turbidity from water collected from the Stradomka river was high-basicity polyaluminum chloride PAX-XL19F, which reduced turbidity from 8.1 to 2.2 NTU (by $73 \%$ ) - Table 1. It was also effective to use this coagulant to reduce the colour of water from 45 to $15 \mathrm{mgPt} / \mathrm{dm}^{3}$ (by $67 \%$ ). Whereas, using the remaining coagulants: medium-basicity PAX-XL10 and low-basicity PAX-18, the turbidity decreases by 50 and $36 \%$, and colour by 44 and $33 \%$, respectively, was obtained.

In the case of purification of water collected from the Adriatyk reservoir, the best effects of turbidity removal were obtained with high-basicity coagulant PAX-XL19F (by 56\%) - Table 2. Using a low-basicity PAX-18, a turbidity reduction of $42 \%$ was achieved. In the case of water colour, the effectiveness of its reduction ranged from 35 to $60 \%$.

Table 1. Mean values of indices for water collected from the Stradomka river in March 2019, before and after the coagulation process

\begin{tabular}{|c|c|c|c|c|c|}
\hline \multirow{2}{*}{ Parameter } & \multirow{2}{*}{ Unit } & \multirow{2}{*}{$\begin{array}{l}\text { Raw water } \\
\text { Stradomka river }\end{array}$} & \multicolumn{3}{|c|}{ Treated water using } \\
\hline & & & PAX-18 & PAX-XL10 & PAX-XL19F \\
\hline $\mathrm{pH}$ & - & 7.06 & 6.72 & 6.80 & 6.85 \\
\hline Turbidity & NTU & 8.14 & 5.20 & 4.05 & 2.17 \\
\hline Colour & $\mathrm{mgPt} / \mathrm{dm}^{3}$ & 45.0 & 30.0 & 25.0 & 15.0 \\
\hline $\mathrm{OC}$ & $\mathrm{mgO}_{2} / \mathrm{dm}^{3}$ & 8.2 & 6.8 & 6.4 & 5.6 \\
\hline TOC & $\mathrm{mgC} / \mathrm{dm}^{3}$ & 14.1 & 11.3 & 10.4 & 8.8 \\
\hline DOC & $\mathrm{mgC} / \mathrm{dm}^{3}$ & 12.2 & 10.5 & 9.7 & 8.3 \\
\hline $\mathrm{UV}_{254}$ & $1 / \mathrm{m}$ & 25.8 & 13.2 & 12.1 & 7.9 \\
\hline SUVA & $\mathrm{dm}^{3} / \mathrm{mg} \cdot \mathrm{m}$ & 2.11 & 1.26 & 1.25 & 0.95 \\
\hline
\end{tabular}


Table 2. Mean values of indices for water collected from the Adriatyk reservoir in March 2019, before and after the coagulation process

\begin{tabular}{|l|c|c|c|c|c|}
\hline \multirow{2}{*}{ Parameter } & \multirow{2}{*}{ Unit } & \multirow{2}{*}{$\begin{array}{c}\text { Raw water } \\
\text { Adriatyk reservoir }\end{array}$} & PAX-18 & PAX-XL10 & PAX-XL19F \\
\cline { 4 - 6 } & & 7.08 & 6.82 & 6.94 & 7.02 \\
\hline pH & - & 5.25 & 3.04 & 3.17 & 2.31 \\
\hline Turbidity & $\mathrm{NTU}$ & 20.0 & 10.0 & 13.0 & 8.0 \\
\hline Colour & $\mathrm{mgPt} / \mathrm{dm}^{3}$ & 4.6 & 3.2 & 3.4 & 3.1 \\
\hline OC & $\mathrm{mgO}_{2} / \mathrm{dm}^{3}$ & 7.6 & 6.5 & 6.4 & 6.2 \\
\hline TOC & $\mathrm{mgC} / \mathrm{dm}^{3}$ & 6.8 & 6.1 & 6.1 & 5.8 \\
\hline DOC & $\mathrm{mgC} / \mathrm{dm}^{3}$ & 8.7 & 4.8 & 4.4 & 4.1 \\
\hline UV & $1 / \mathrm{m}$ & 1.28 & 0.77 & 0.72 & 0.71 \\
\hline SUVA & $\mathrm{dm} 3 / \mathrm{mg} \cdot \mathrm{m}$ & & & & \\
\hline
\end{tabular}

Table 3. Mean values of indices for water collected from the Stradomka river and the Adriatyk reservoir in June 2019, before and after the coagulation process

\begin{tabular}{|c|c|c|c|c|c|}
\hline Parameter & Unit & $\begin{array}{c}\text { Raw water } \\
\text { Stradomka river }\end{array}$ & $\begin{array}{l}\text { Treated water } \\
\text { PAX-XL19F }\end{array}$ & $\begin{array}{c}\text { Raw water } \\
\text { Adriatyk reservoir }\end{array}$ & $\begin{array}{c}\text { Treated water } \\
\text { PAX-XL19F }\end{array}$ \\
\hline $\mathrm{pH}$ & - & 7.57 & 7.53 & 7.94 & 7.78 \\
\hline Turbidity & NTU & 20.52 & 6.71 & 6.04 & 2.09 \\
\hline Colour & $\mathrm{mgPt} / \mathrm{dm}^{3}$ & 45.0 & 20.0 & 15.0 & 7.0 \\
\hline $\mathrm{OC}$ & $\mathrm{mgO}_{2} / \mathrm{dm}^{3}$ & 9.3 & 5.4 & 4.8 & 3.4 \\
\hline TOC & $\mathrm{mgC} / \mathrm{dm}^{3}$ & 11.8 & 8.4 & 7.6 & 6.3 \\
\hline $\mathrm{DOC}$ & $\mathrm{mgC} / \mathrm{dm}^{3}$ & 10.7 & 7.8 & 6.6 & 5.7 \\
\hline $\mathrm{UV}_{254}$ & $1 / \mathrm{m}$ & 23.0 & 10.5 & 8.5 & 5.2 \\
\hline SUVA & $\mathrm{dm}^{3} / \mathrm{mg} \cdot \mathrm{m}$ & 2.15 & 1.35 & 1.29 & 0.91 \\
\hline
\end{tabular}

After the coagulation process conducted with the usage of the medium-basicity PAX$\mathrm{XL10}$, the content of organic compounds in water collected from the Stradomka river, assayed as oxygen consumption OC and total organic carbon TOC, decreased respectively from $8.2 \mathrm{mgO} / \mathrm{dm}^{3}$ and $14.1 \mathrm{mgC} / \mathrm{dm}^{3}$ to $6.4 \mathrm{mgO}_{2} / \mathrm{dm}^{3}$ and $10.4 \mathrm{mgC} / \mathrm{dm}^{3}$. With the usage of the lowbasicity polyaluminium chloride PAX-18, OC reduction down to $6.8 \mathrm{mgO}_{2} / \mathrm{dm}^{3}$ and TOC content down to $11.3 \mathrm{mgC} / \mathrm{dm}^{3}$ were obtained. The best effects of reducing the content of organic compounds were obtained using high-basicity coagulant PAX-XL19F. The TOC content in water after the coagulation amounted to $8.8 \mathrm{mgC} / \mathrm{dm}^{3}$, and $\mathrm{OC}-5.6 \mathrm{mgO}_{2} / \mathrm{dm}^{3}$. This means a decrease in the value of these indicators by $38 \%$ and $32 \%$, respectively (Fig. 1). Also in the case of purifying water from the Adriatyk reservoir, the best results were obtained after applying high-basicity coagulant.

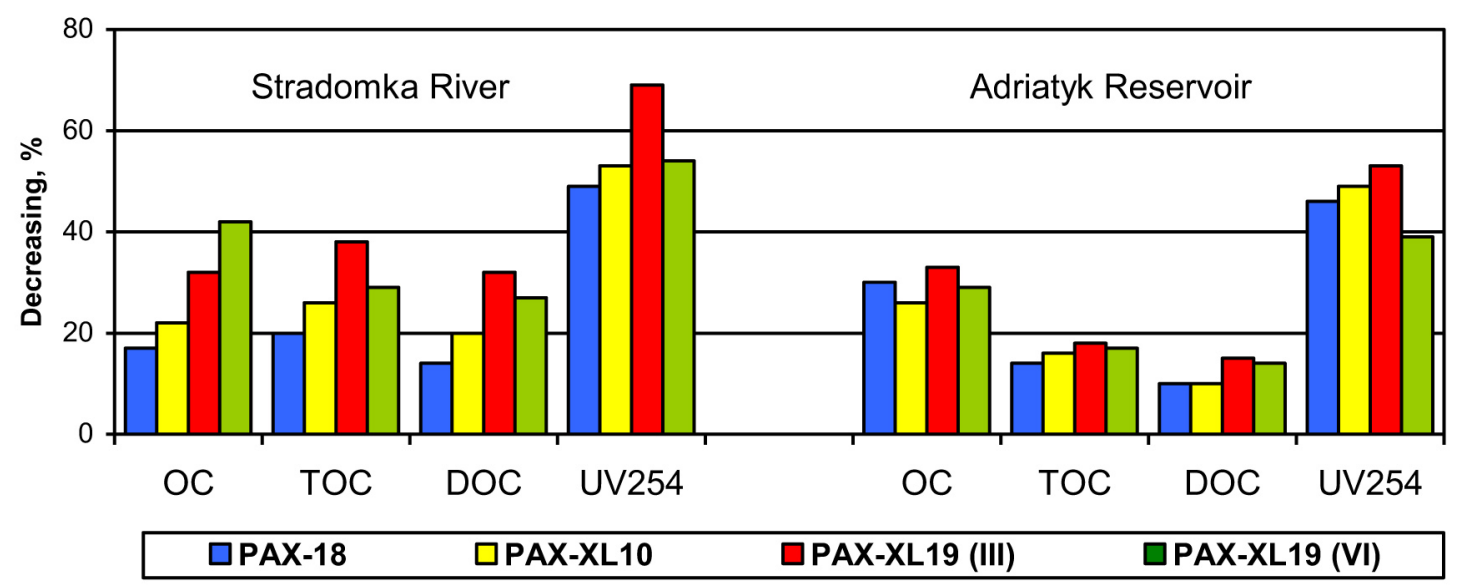

Fig. 1. Decreasing of OC, TOC, DOC and UV absorbance after the coagulation process (III - March, VI - June) 
The TOC content decreased from 7.6 to $6.2 \mathrm{mgC} /$ $\mathrm{dm}^{3}$, and $\mathrm{OC}$ from 4.6 to $3.1 \mathrm{mgO} / \mathrm{dm}^{3}$, which indicates a decrease by $18 \%$ and $33 \%$, respectively. In the case of studies carried out in June, the TOC content and OC in waters after coagulation decreased by $17-42 \%$ (Fig. 1).

In the conducted research (at $\mathrm{pH}$ 6.7-7.9), a reduction in DOC content in water after the coagulation by $10-32 \%$ and $\mathrm{UV}_{254}$ absorbance by $39-69 \%$ was obtained, depending on the coagulant used (Fig. 1). A significant reduction in the value of these indicators was reported with the usage of high-basicity polyaluminium chloride PAX-XL19F. It is believed [Matilainen et al. 2010] that a significant decrease in the absorbance value during coagulation is obtained by removal of hydrophobic and remaining of hydrophilic DOC fraction. The SUVA index for untreated water was $1.28 \div 2.15 \mathrm{~m}^{2} / \mathrm{g}$ C. As demonstrated in [Machi and Mołczan 2016], this value in the range of $2 \div 4 \mathrm{~m}^{2} / \mathrm{g} \mathrm{C}$ indicates a mixture of humic and non-humic, hydrophilic and hydrophobic substances (high and low molecular) in surface water, with the effectiveness of DOC removal in the process of coagulation ranging from 25 to $50 \%$ if aluminium salts are used. The $\mathrm{SUVA}_{254}$ value of water after the coagulation was equal to $0.71-1.35 \mathrm{~m}^{2} / \mathrm{g} \mathrm{C}$. This indicates that in water after the coagulation, organic substances that are difficult to remove in this process remained. The $\mathrm{SUVA}_{254}$ value $<2 \mathrm{~m}^{2} / \mathrm{gC}$ suggests the presence of mostly non-humics, low hydrophobicity, low molar mass compounds.

Analysis of the literature data does not allow for an unequivocal determination of the efficiency of coagulants in the removal of organic substances from water intended for human consumption [Sillanpää et al. 2018]. Significant discrepancies in the results can be explained by both the complex structure of organic compounds and the diversity of commercial coagulants whose accurate chemical composition is unknown. Basicity is one of the key parameters that can affect the properties of polyaluminium chlorides and the consequent performance of coagulation [Zhang et al. 2018].

The use of polyaluminium chlorides for the removal of organic substances was examined by Yang et al. [2011]. They used polyaluminium chlorides with basicity of 67 , and $77 \%$. At $\mathrm{pH} 7$, the researchers achieved the effects of reducing $\mathrm{UV}_{254}$ absorbance by 45 , and $38 \%$, respectively. Furthermore, the DOC contents decreased by 29 and $12 \%$. Better results were obtained for a coagulant with basicity of $67 \%$ compared to that with basicity of $77 \%$. Polyaluminium chlorides contain significant amounts of polycationic pre-hydrolysis products. Polymer forms of aluminium are considered stable, while monomeric forms may be transformed. This can lead to the formation of in-situ aluminium polymers that neutralize the pollutant load under certain conditions. Therefore, good water treatment efficiency can be obtained using coagulants with lower basicity, containing significant amounts of monomeric forms.

In collected surface water as well as in water after the coagulation process, the presence of trihalomethanes was not discovered. However, their presence was demonstrated in these waters after the chlorination process. THM concentrations in water from the Stradomka river and from the Adriatyk reservoir subjected to chlorination for 24 hours and in those waters previously treated in the coagulation process and then subjected to chlorination for 24 hours are presented in Tables 4 to 7 .

The presence of $\mathrm{CHCl}_{3}, \mathrm{CHCl}_{2} \mathrm{Br}, \mathrm{CHClBr}_{2}$ was found in analyzed water after the chlorination process, $\mathrm{CHBr}_{3}$ was not detected. The highest concentration was found for $\mathrm{CHCl}_{3}$. In the

Table 4. THM concentrations in chlorinated water collected from the Stradomka in March 2019 and in chlorinated water treated in the coagulation process

\begin{tabular}{|c|c|c|c|c|c|}
\hline \multirow{2}{*}{ Parameter } & \multirow{2}{*}{ Unit } & \multirow{2}{*}{$\begin{array}{c}\text { Raw water } \\
\text { Stradomka river }\end{array}$} & \multicolumn{3}{|c|}{ Treated water using } \\
\hline & & & PAX-18 & PAX-XL10 & PAX-XL19F \\
\hline $\mathrm{CHCl}_{3}$ & $\mu \mathrm{g} / \mathrm{dm}^{3}$ & 438.0 & 271.0 & 252.0 & 190.0 \\
\hline $\mathrm{CHCl}_{2} \mathrm{Br}$ & $\mu \mathrm{g} / \mathrm{dm}^{3}$ & 29.3 & 25.4 & 23.7 & 19.2 \\
\hline $\mathrm{CHClBr}_{2}$ & $\mu \mathrm{g} / \mathrm{dm}^{3}$ & 1.6 & 1.5 & 1.6 & 1.4 \\
\hline $\mathrm{CHBr}_{3}$ & $\mu \mathrm{g} / \mathrm{dm}^{3}$ & nd & nd & nd & nd \\
\hline THM-PF & $\mu \mathrm{gCHCl} / \mathrm{dm}^{3}$ & 460.3 & 290.4 & 270.2 & 204.8 \\
\hline
\end{tabular}

nd - not detected 
Table 5. THM concentrations in chlorinated water collected from the Adriatyk reservoir in March 2019 and in chlorinated water treated in the coagulation process

\begin{tabular}{|c|c|c|c|c|c|}
\hline \multirow{2}{*}{ Parameter } & \multirow{2}{*}{ Unit } & \multirow{2}{*}{$\begin{array}{c}\text { Raw water } \\
\text { Adriatyk reservoir }\end{array}$} & \multicolumn{3}{|c|}{ Treated water Rusing coagulant } \\
\hline & & & PAX-18 & PAX-XL10 & PAX-XL19F \\
\hline $\mathrm{CHCl}_{3}$ & $\mu \mathrm{g} / \mathrm{dm}^{3}$ & 163.0 & 108.0 & 112.0 & 95.0 \\
\hline $\mathrm{CHCl}_{2} \mathrm{Br}$ & $\mu \mathrm{g} / \mathrm{dm}^{3}$ & 26.1 & 22.4 & 25.2 & 23.0 \\
\hline $\mathrm{CHClBr}_{2}$ & $\mu \mathrm{g} / \mathrm{dm}^{3}$ & 3.5 & 4.3 & 4.0 & 4.1 \\
\hline $\mathrm{CHBr}_{3}$ & $\mu \mathrm{g} / \mathrm{dm}^{3}$ & nd & nd & nd & nd \\
\hline THM-PF & $\mu \mathrm{gCHCl}_{3} / \mathrm{dm}^{3}$ & 184.0 & 126.8 & 132.6 & 114.1 \\
\hline
\end{tabular}

nd - not detected

Table 6. THM concentrations in chlorinated waters collected in June 2019 and in chlorinated waters treated in the coagulation process

\begin{tabular}{|l|c|c|c|c|c|}
\hline \multicolumn{1}{|c|}{ Parameter } & Unit & $\begin{array}{c}\text { Raw water } \\
\text { Stradomka }\end{array}$ & $\begin{array}{c}\text { Treated water } \\
\text { PAX-XL19F }\end{array}$ & $\begin{array}{c}\text { Raw water } \\
\text { Adriatyk }\end{array}$ & $\begin{array}{c}\text { Treated water } \\
\text { PAX-XL19F }\end{array}$ \\
\hline $\mathrm{CHCl}_{3}$ & $\mu \mathrm{g} / \mathrm{dm}^{3}$ & 457.0 & 283.0 & 265.0 & 164.0 \\
\hline $\mathrm{CHCl}_{2} \mathrm{Br}$ & $\mu \mathrm{g} / \mathrm{dm}^{3}$ & 34.6 & 34.0 & 38.2 & 29.7 \\
\hline $\mathrm{CHClBr}_{2}$ & $\mu \mathrm{g} / \mathrm{dm}^{3}$ & 3.1 & 3.3 & 5.3 & 5.8 \\
\hline $\mathrm{CHBr}$ & $\mu \mathrm{g} / \mathrm{dm}^{3}$ & nd & nd & nd & $\mathrm{nd}$ \\
\hline $\mathrm{THM}-\mathrm{PF}$ & $\mu \mathrm{gCHCl} / \mathrm{dm}^{3}$ & 484.0 & 314.6 & 296.0 & 189.0 \\
\hline
\end{tabular}

nd - not detected

Table 7. THM concentrations in chlorinated water collected in June 2019 and in chlorinated water treated in the coagulation process (after water filtration through $0.45 \mu \mathrm{m}$ membrane filter)

\begin{tabular}{|l|c|c|c|c|c|}
\hline \multicolumn{1}{|c|}{ Parameter } & Unit & $\begin{array}{c}\text { Raw water } \\
\text { Stradomka }\end{array}$ & $\begin{array}{c}\text { Treated water } \\
\text { PAX-XL19F }\end{array}$ & $\begin{array}{c}\text { Raw water } \\
\text { Adriatyk }\end{array}$ & $\begin{array}{c}\text { Treated water } \\
\text { PAX-19XLF }\end{array}$ \\
\hline $\mathrm{CHCl}_{3}$ & $\mu \mathrm{g} / \mathrm{dm}^{3}$ & 404.0 & 228.0 & 201.0 & 128.0 \\
\hline $\mathrm{CHCl}_{2} \mathrm{Br}$ & $\mu \mathrm{g} / \mathrm{dm}^{3}$ & 33.1 & 28.2 & 31.3 & 25.1 \\
\hline $\mathrm{CHClBr}$ & $\mu \mathrm{g} / \mathrm{dm}^{3}$ & 2.9 & 3.1 & 4.8 & 5.2 \\
\hline $\mathrm{CHBr}$ & $\mu \mathrm{g} / \mathrm{dm}^{3}$ & $\mathrm{nd}$ & $\mathrm{nd}$ & $\mathrm{nd}$ & $\mathrm{nd}$ \\
\hline $\mathrm{THM}-\mathrm{PF}$ & $\mu \mathrm{gCHCl} / \mathrm{dm}^{3}$ & 429.8 & 250.3 & 226.5 & 149.3 \\
\hline
\end{tabular}

nd - not detected

case of the water collected from the Stradomka river and chlorinated in March and June 2019, the concentrations were 438 and $457 \mu \mathrm{g} / \mathrm{dm}^{3}$, respectively, while in the water collected from Adriatyk reservoir these values were 163 and $265 \mu \mathrm{g} / \mathrm{dm}^{3}$, respectively.

Whereas, in waters chlorinated after their previous purification in the coagulation process, the concentration of $\mathrm{CHCl}_{3}$ ranged from 190 to $288 \mu \mathrm{g} / \mathrm{dm}^{3}$, and from 95 to $164 \mu \mathrm{g} / \mathrm{dm}^{3}$, respectively. The lowest concentration of $\mathrm{CHCl}_{3}$ was obtained in March when high-basicity polyaluminium chloride PAX-XL19F were used for the coagulation process. The concentration of $\mathrm{CHCl}_{3}$ was lower by 42 and $57 \%$, than in the untreated surface water subjected to chlorination (Fig. 2). The highest concentration of $\mathrm{CHCl}_{3}$ in March was obtained in chlorinated waters, which were purified in the coagulation process using a lowbasicity coagulant PAX-18 for water from the Stradomka river, and a medium-basicity coagulant PAX-XL10 for water from the Adriatyk reservoir (Table 4 and Table 5).

The concentration of $\mathrm{CHCl}_{2} \mathrm{Br}$ in the untreated water subjected to chlorination was from 26 to $38 \mu \mathrm{g} / \mathrm{dm}^{3}$, whereas in the water treated by coagulation and chlorinated, this value ranged from 19 to $34 \mu \mathrm{g} / \mathrm{dm}^{3}$. The $\mathrm{CHClBr}_{2}$ content was from 1.4 to $5.8 \mu \mathrm{g} / \mathrm{dm}^{3}$. The concentration of trichloromethane accounted for $78 \div 93 \%$ of the total THM content in the chlorinated waters. The high formation of $\mathrm{CHCl}_{3}$ is in accordance with previous findings regarding THM formation within drinking water [Clayton et al. 2019]. 


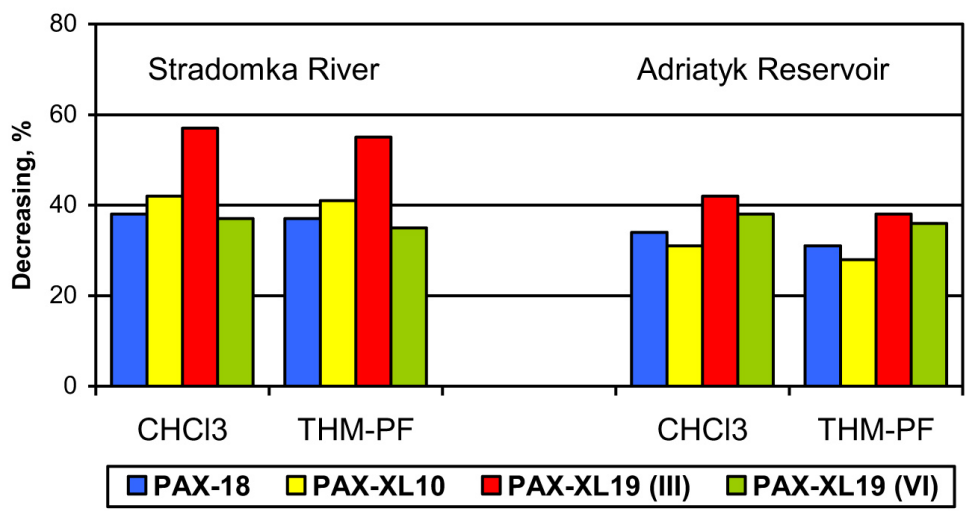

Fig. 2. Decreasing of $\mathrm{CHCl}_{3}$ concentration and of THMPF value in chlorinated water treated by coagulation (III - March, VI - June)

The potential for formation of THM-PF trihalomethanes in the untreated water ranged from 184 to $484 \mu \mathrm{gCHCl} / \mathrm{dm}^{3}$, whereas in the water after coagulation and chlorination, it ranged from 114 to $314 \mu \mathrm{gCHCl}_{3} / \mathrm{dm}^{3}$. A reduction in THM-PF was $28-55 \%$ (the highest values were found for water from the Stradomka river in March 2019) Fig. 2. Matilainen et al. [2010] argues that in waters treated by coagulation, a reduction in the potential of THM formation can reach from 25 to $66 \%$.

The amount of $\mathrm{CHCl}_{3}$ produced from undissolved (UDOC) and dissolved organic carbon (DOC) in raw water and in water treated in the coagulation process and subjected to chlorination for 24 hours is presented in Table 8 .

The amount of $\mathrm{CHCl}_{3}$ formed in chlorinated raw waters from UDOC in the case of waters from the Stradomka river and the Adriatyk reservoir collected in June was equal to 12 and 24\% of total amount, respectively, while in chlorinated waters treated in the coagulation process 21 and $22 \%$. The remaining amount originated from DOC. Therefore, in order to reduce the formation of THM, it is important to increase DOC removal, e.g. by coagulation enhancement with the process of ozonation and/or adsorption [Wang et al. 2017].

\section{CONCLUSIONS}

In the laboratory conditions of the process using pre-hydrolysed coagulants (PAX-18, PAX-XL10, PAX-XL19F), reductions in oxygen consumption, TOC and DOC contents depending on the month and place when water was collected were $17 \div 42 \%, 14 \div 38 \%$ and $10 \div 32 \%$, respectively, whereas reduction in $\mathrm{UV}_{254}$ absorbance ranged from 39 to $69 \%$. The best results were obtained using high-basicity polyaluminium chloride PAX-XL19F.

The study confirmed the usefulness of the coagulation process in the removal of organic matter, which represents a precursor for formation of trihalomethanes. The potential for THM formation in treated water was by $28 \div 55 \%$ lower than in untreated surface water after chlorination. The concentration of trichloromethane was $78 \div 93 \%$ of the total THM content in the chlorinated treated waters. Dissolved organic matter played a major role in $\mathrm{CHCl}_{3}$ formation.

\section{Acknowledgement}

This research was supported by Czestochowa University of Technology, project BS-PB-400-301/19.

Table 8. The amount of $\mathrm{CHCl}_{3}$ produced in chlorinated raw and treated waters from UDOC and DOC in the case of waters from the Stradomka river and the Adriatyk reservoir collected in June

\begin{tabular}{|l|c|c|c|c|}
\hline \multirow{2}{*}{$\mathrm{CHCl}_{3}$ resulting from } & \multicolumn{2}{|c|}{ Amount of $\mathrm{CHCl}_{3}$ produced in raw waters, \% } & \multicolumn{2}{c|}{ Amount of $\mathrm{CHCl}_{3}$ produced in treated waters, \% } \\
\cline { 2 - 5 } & Stradomka river & Adriatyk reservoir & Stradomka river & Adriatyk reservoir \\
\hline UDOC & 12 & 24 & 21 & 22 \\
\hline DOC & 88 & 76 & 79 & 78 \\
\hline
\end{tabular}




\section{REFERENCES}

1. Bhatnagar A., Sillanpää M. 2017. Removal of natural organic matter (NOM) and its constituents from water by adsorption. A review. Chemosphere, 166, 497-510.

2. Clayton G.E., Thorn R.M.S, Reynolds D.S. 2019. Comparison of trihalomethane formation using chlorine-based disinfectants within a model system; applications within point-of-use drinking water treatment. Frontiers in Environmental Science, 7, 35, 1-13.

3. Dąbrowska L. 2018. The use polyaluminium chlorides with various basicity for removing organic matter from drinking water. Desalination and Water Treatment, 134, 80-85.

4. Font-Ribera L., Colomer Cotta J., Gómez-Gutiérrez A., Villanueva C.M. 2017. Trihalomethane concentrations in tap water as determinant of bottled water use in the city of Barcelona. Journal of Environmental Sciences, 58, 77-82.

5. Golea D.M., Upton A., Jarvis P., Moore G., Sutherland S., Parsons S.A., Judd S.J. 2017. THM and HAA formation from NOM in raw and treated surface waters. Water Research, 112, 226-235.

6. Guidelines for Drinking-water Quality. 2011. 4th ed. World Health Organization, Geneva.

7. Kaleta J., Puszkarewicz A. 2019. Influence of water hardness on the effectiveness of coagulation of humic compounds. Journal of Ecological Engineering, 20(6), 126-134.

8. Machi J., Mołczan M. 2016. Methods for natural organic matter characterization in water taken and treated for human consumption, Environmental Protection, 38(4), 25-32 (in Polish).

9. Marais S.S., Ncube E.J., Msagati T.A.M., Mamba B.B., Nkambule T.T.I. 2019. Assessment of trihalomethane (THM) precursors using specific ultrafiolet absorbance (SUVA) and molecular size distribution (MSD). Journal of Water Process Engineering, 27, 143-151.

10. Matilainen A., Vepsäläinen M., Sillanpää M. 2010. Natural organic matter removal by coagulation during water treatment. A review. Advances in Colloid and Interface Science, 159, 189-197.

11. Nawrocki J. (Ed.) 2010. Water treatment. Physical, chemical and biological processes. PWN Scientific Publishing, Warszawa - Poznań (in Polish).
12. Niu Z.-G., Hu X.-P., Zhang Y., Sun Y.-Y. 2017. Effect of chlorine dose in prechlorination on trihalomethanes and haloacetic acids during water treatment process. Environmental Science and Pollution Research, 24, 5068-5077.

13. Regulation of the Minister of Health from 7 December 2017 on the quality of water intended for human consumption, item 2294.

14. Sillanpää M., Ncibi M.Ch., Matilainen A., Vepsäläinen M. 2018. Removal of natural organic matter in drinking water treatment by coagulation: A comprehensive review. Chemosphere, 190, 54-71.

15. Sperczyńska E., Dąbrowska L., Wiśniowska E. 2016. Removal of turbidity, colour and organic matter from surface water by coagulation with polyaluminium chlorides and with activated carbon as coagulant aid. Desalination and Water Treatment, 57(3), 1139-1144.

16. Standard methods for the examination of water and wastewater. 1998. 20th ed. American Public Health Association, Washington, DC.

17. Wang F., Gao B., Yue Q., Bu F., Shen X. 2017. Effects of ozonation, powdered activated carbon adsorption, and coagulation on the removal of disinfection by-product precursors in reservoir water. Environmental Science and Pollution Research, 24, 17945-17954.

18. Yang Z., Gao B., Wang Y., Wang Q., Yue Q. 2011. Aluminum fractions in surface water from reservoirs by coagulation treatment with polyaluminum chloride (PAC): Influence of initial $\mathrm{pH}$ and $\mathrm{OH}-/$ $\mathrm{Al3}+$ ratio. Chemical Engineering Journal, 170, 107-113.

19. Zainudin F.M., Hasan H.A., Abdullah S.R.S. 2018. An overview of the technology used to remove trihalomethane (THM), trihalomethane precursors, and trihalomethane formation potential (THMFP) from water and wastewater. Journal of Industrial and Engineering Chemistry, 57, 1-14.

20. Zhang Z., Jing R., He S., Qian J., Zhang K., Ma G., Chang X., Zhang M., Li Y. 2018. Coagulation of low temperature and low turbidity water: Adjusting basicity of polyaluminum chloride (PAC) and using chitosan as coagulant aid. Separation and Purification Technology, 206, 131-139. 